\title{
The Influence of the Technological Process on the Surface Quality and Tribological Properties of Powder Details
}

\author{
Armands Leitans ${ }^{1}$, Irina Boiko ${ }^{1}$, Janis Lungevics ${ }^{1}$, Viktors Mironovs ${ }^{2}$ \\ ${ }^{1}$ Riga Technical University, Faculty of Transport and Mechanical Engineering, Institute of \\ Mechanical Engineering, Address: Ezermalas 6k, Riga, LV-1006, Latvia \\ ${ }^{2}$ Riga Technical university, Faculty of Civil Engineering, Scientific Laboratory of Powder \\ Materials, Azenes 16/20, LV-1048, Riga, Latvia
}

\begin{abstract}
Nowadays the materials made by methods of powder metallurgy are widely used for producing details of the heavy-duty friction pair. Due to high reliability and effective combination of mechanical and tribological properties such materials are usually used in transport industry, for example for gear assemblies of different kinds of automobiles, brake system of high speed trains, aircrafts etc. There are many variations of powder materials, but for friction pairs the iron based antifriction materials, for example Fe-C-Cu, Fe-P, Fe-Cu-Sn, Fe-Cu-Sn-Pb-MoS ${ }_{2}$, Fe-C$\mathrm{Cu}-\mathrm{Ni}$-Mo and others are successfully used. In recent years, the requirements for antifriction materials are raised highly because of more intensive freight traffic and speed of vehicles. On the other hand, the demand of more inexpensive materials and effective using of natural resources is the issue of the day.

The aim of this paper is to offer the new low-cost metal powder material based on Fe-C compound with content of $\mathrm{Ni}$ and Mo up to $\mathbf{0 . 3 \%}$. The influence of the parameters of technological process (pressing and sintering) on physical properties (porosity, density), mechanical properties (hardness) as well as on 2D roughness and 3D texture parameters was studied and is presented in this paper as well. The "Taylor Hobson Ltd" 3D measurement system has been used in metrological study. The analysis of the influence of the technological process on the surface roughness parameters is given. The tribological properties (friction coefficient) were evaluated using "ball-on-disk" testing without lubrication. The analysis of achieved results is prove the appropriateness of using of new low-alloy metal powder material on the iron base for producing details of friction pair. One of the possible applications - bushes for braking systems of railway rolling stock. Using offered material allows reducing the product cost in complex with acceptable wear resistance and durability.
\end{abstract}

Keywords: materials testing, surface roughness, friction.

\section{INTRODUCTION}

Powder Metallurgy (PM) is a materials processing technology to create new materials and parts by diffusing different metal powders as raw ingredients through the sintering process after mixing and compacting. PM has grown with the expansion of various industries since middle of 20th century. Nowadays, over 90\% PM products including details of the heavy-duty friction pairs like automotive braking systems are used in the transportation market of all kinds (air, ground and water transport) [1].

Modern tribomaterials consist of composites made by PM with metallic matrix from iron, copper or aluminum reinforced with a) friction components (as oxides: $\mathrm{Al}_{2} \mathrm{O}_{3}, \mathrm{ZrO}_{2}, \mathrm{SiO}_{2}$, carbide: $\mathrm{TiC}, \mathrm{SiC}, \mathrm{B}_{4} \mathrm{C}$, nitrides: TiN, $\mathrm{Si}_{3} \mathrm{~N}_{4}$ ) with role of friction and improving of the wear resistance and b) lubrication components (graphite, molybdenum disulfide, etc.), with the role of increasing material resistance to gripping and for wear reduction of disc (rotor) brake [2]. Iron and copper have been used extensively for various tribological applications [1] - [3]. The copper and iron-based antifriction materials are most often fabricated using PM technique due to its many advantages such as the elimination of solidification induced chemical segregation and structural defects often accompanied with melting and solidification processes. The ease in mixing of different powders leads to the possibility for developing new composite materials with special physical and mechanical properties that are otherwise difficult to manufacture [3].

In the recent years iron-based sintered bearings production was considerably increased at the expense of the copper-based ones, due to the low cost and availability of the iron powders as well as their higher strength [4], [5]. It should be mentioned here, that mixtures of iron and copper powder have a twofold 
benefits: 1) copper melts at $1094^{\circ} \mathrm{C}$, i.e. below sintering temperature, and rapidly infiltrates the pore system of the compact from where it diffuses relatively easily into the iron powder particles; 2) copper is dissolvable in $\gamma$-iron (austenite) up to approx. 9 wt.- $\%$, but only up to 0,4 wt. $-\%$ in $\alpha$-iron (ferrite); consequently, iron-copper alloys can be precipitation-hardened by low-temperature annealing after sintering - and actually do so to a certain extend already on passing the cooling zone of the sintering furnace [6].

Good results were achieved by adding nickel and molybdenum, but the costs of such elements rise rapidly in recent years [1]. In some cases the cost of expensive alloying elements can be avoided and micro-alloying can be applied. In micro-alloying the amount of additive usually is from 0.1 to $5 \%$. Some authors assumed that dispersed additives have great potential for microalloying and nanoalloying [1], [7], [8]. Thus, the introduction of nanopowders of copper or copper-iron ligature into a powder iron-based material has led to an increase in strength, hardness, density, and to reduce in sintering temperature [8].

The demand of more inexpensive antifriction materials and effective using of natural resources is the issue of the day. The aim of this paper is to offer the new low-cost metal powder material based on $\mathrm{Fe}$ $\mathrm{C}$ compound with content of $\mathrm{Ni}$ and Mo up to $0.3 \%$.

It is known that the quality of contact surfaces together with dimensional tolerance and properties of powder parts are very important for tribological applications [9] - [11]. Surface condition of powder parts on the different stages of producing is the important factor that influences on the exploitation properties and running ability of product. The investigation of the influence of the technological process (pressing and sintering) on surface quality and tribological properties of powder parts produced from new micro-alloyed powder material was done for proving the possibility of using such material for producing the details for the friction pairs.

\section{MATERIALS AND METHODS}

The view of fragments of powder parts after different stages of production (two-side compacting and following sintering) is shown on Fig. 1.

For investigation the following powder mixture (from powders produced by „Höganäs AB”, Sweden) was used (mass \%): Fe 96.5\%, Ni $0.22 \%$, Cu 2.27\%, Mo $0.28 \%$, S $0.04 \%$, P $0.01 \%$, C $0.6 \%$, Kennolube (graphite lubricant) $0.7 \%$. The main properties of offered low-alloy metal powder material are the following: apparent density $3.15 \mathrm{~g} / \mathrm{cm}^{3}$; flow 40 sec/50g; compressibility $6.80 \mathrm{~g} / \mathrm{cm}^{3}$. Powder parts (Fig. 1) were produced by the following steps: 1) twoside compacting was carried out on the hydraulic press in the closed die at pressure up to $600 \mathrm{MPa}$;
2) sintering was realised in the endogas atmoshere at the temperature $1120^{\circ} \mathrm{C}$, retention time $40 \mathrm{~min}$.

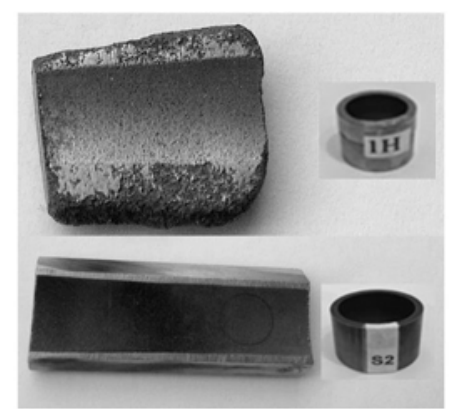

Fig.1. Fragments and view of powder parts after compacting (H1) and following sintering (S2): outer diameter 25 (45) mm, inner diameter 11 (29) mm, length 22 (31) mm correspondingly.

After compacting the porosity of powder parts was up to $23 \%$, density - up to $6.9 \mathrm{~g} / \mathrm{cm}^{3}$. Sintered density of the parts was up to $7.1 \mathrm{~g} / \mathrm{cm}^{3}$, porosity $20 \%$, tensile

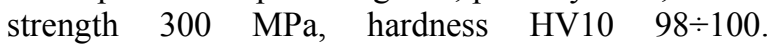
Methodology for the investigation of the properties of powder parts which was used in our investigation is given in [12].

For metrological study of surface quality of the powder parts on the different stages of producing (after compacting and after compacting and sintering) the "Taylor Hobson Ltd" 3D measurement system was used. This system allows roughness and waviness filtration out of measured (primary surface) that gives better understanding of surface structure and manufacturing process as well it can be used for creating surface $3 \mathrm{D}$ photo simulation images etc. $2 \mathrm{D}$ and 3D measurements with stylus instrument were achieved by basic "stepping" method (Fig. 2) and data processing by computer [13].

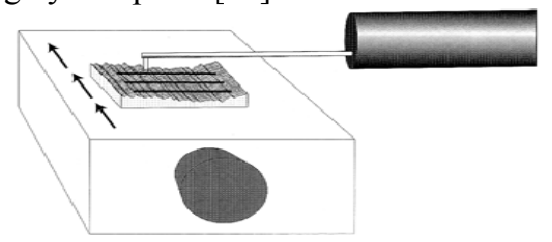

Fig.2. Principal scheme of basic "stepping" method used by stylus systems [13].

Tribological study was done using tribometer made by "CSM Instruments" (Switzerland), besides testing conforms to the following standards DIN 50324 "Tribology; testing of friction and wear model test for sliding friction of solids (ball-on-disc system)", ASTM G99 "Standard test method for wear testing with a pin-on-disk apparatus" and ASTM G133 "Standard test method for linear reciprocating Ball-onflat sliding wear". The friction coefficient was evaluated using "ball-on-disk" testing without lubrication, when the tested example was used as a disc, but a high-strength steel ball was used as a counter-body. The principal scheme of testing is 
shown on Fig. 3. Experimental settings are shown in Table I.

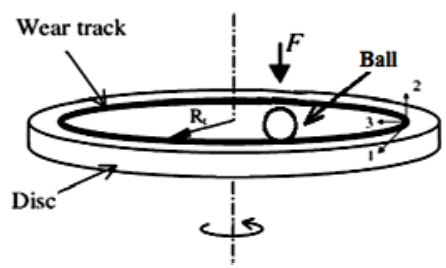

Fig.3. Principal scheme of ball-on-disk testing: $\mathrm{F}$ is the normal force applied on the ball, $\mathrm{R}$ is the radius of the wear track.

TABLE I

EXPERIMENTAL SETTINGS

\begin{tabular}{|l|l|}
\hline Testing parameters: & Value/type of testing parameters: \\
\hline Force & $3 \mathrm{~N}$ \\
\hline Measurement period & $20 \mathrm{~s}$ \\
\hline Linear velocity & $0.05 \mathrm{~m} / \mathrm{s}$ \\
\hline Radius of ball's contact & $3 \mathrm{~mm}$ \\
\hline Distance & $1 \mathrm{~m}$ \\
\hline Diameter of the ball & $6 \mathrm{~mm}$ \\
\hline Material of the ball & $100 \mathrm{Cr} 6$ (DIN EN ISO 683-17) \\
\hline Material of the sample & $\mathrm{H} 1, \mathrm{~S} 2$ \\
\hline Liquid for surface cleaning & Alcohol solution \\
\hline Atmosphere & Air \\
\hline Temperature & $21^{\circ} \mathrm{C}$ (room) \\
\hline Moisture & $46^{\circ}$ (room) \\
\hline
\end{tabular}

\section{RESULTS AND DISCUSSION}

The influence of the technological process on the surface quality and tribological properties of powder parts, produced from new low-cost metal powder material, was investigated by measurement and comparison of the average $2 \mathrm{D}$ roughness parameters and 3D (surface) texture parameters of powder parts after compacting and following sintering and by measurement and analysis of the friction coefficient as well.

\section{A. $2 D$ roughness parameters}

The 2D amplitude roughness parameters (according to ISO 4287 "Surface texture: Profile method - Terms, definitions and surface texture parameters") Ra arithmetic mean roughness and $\mathrm{Rz}$ - maximum height of profile were measured. Comparison of 2D amplitude roughness parameters of powder parts on the different stages of producing is given in Table II. As shown the $\mathrm{Ra}$ and $\mathrm{Rz}$ values increases after sintering.

Some researches assume, that surface texture metrology gives a better understanding of the surface in its functional state since in practical applications surface roughness of the machine parts behaves as a 3D object [14] - [17].
TABLE II

COMPARISON OF 2D AMPLITUDE ROUGHNESS PARAMETERS

\begin{tabular}{|l|c|c|}
\hline Powder parts after: & $\mathrm{Ra}, \mu \mathrm{m}$ & $\mathrm{Rz}, \mu \mathrm{m}$ \\
\hline compacting & 1.56 & 7.76 \\
\hline sintering & 2.37 & 11.2 \\
\hline
\end{tabular}

\section{B. $3 D$ texture parameters}

Achieved 3D surface images of the powder parts after compacting and following sintering are given on Fig. 4 and Fig. 5 respectively. The following 3D texture parameters (according to EN ISO 25178-2 "Surface texture: Areal - Part 2: Terms, definitions

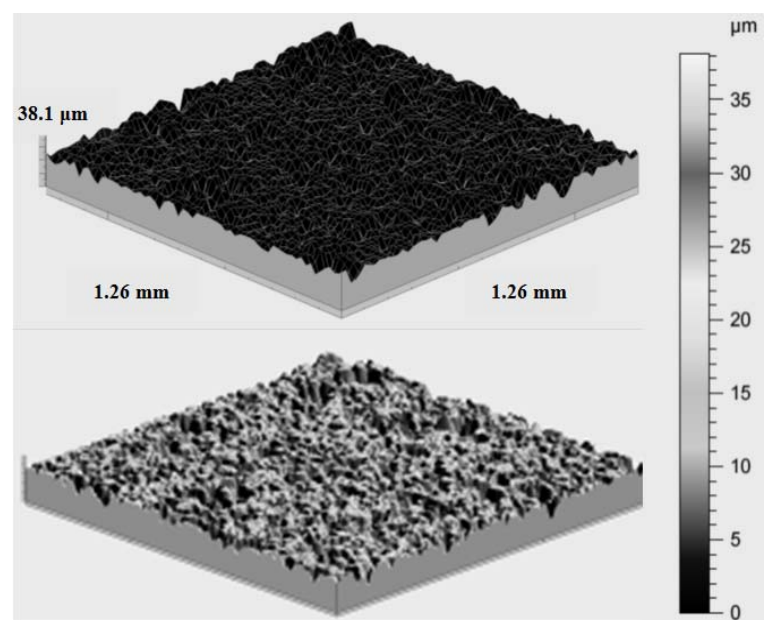

Fig.4. View of the 3D surface image and photo simulation of the powder part after compacting.

and surface texture parameters" and [13]) were measured and analyzed: 1) amplitude parameters: Sa, Ssk; 2) spatial parameter: Str, 3) functional (material volume) parameter: Vmc, 4) hybrid parameter: Sfd. Such choice of texture parameters is based on its essence and significance for friction surfaces of the powder parts:

- Sa - arithmetic mean of the deviations from the mean plane, represent an overall measure of the texture comprising the surface;

- Ssk - skewness of the scale-limited surface, represents the degree of symmetry of the surface heights about the mean plane;

- Str - texture aspect ratio of the surface, measures the isotropy of surface;

- Vmc - core material volume of the scalelimited surface, indicate a measure of the material forming the surface between various heights;

- Sfd - fractal dimension of the surface (complexity of the surface), smaller value specifies the more periodical surface (different from the random surface). 
Comparison of the mentioned 3D texture parameters of powder parts after compacting and following sintering is given in Table III.

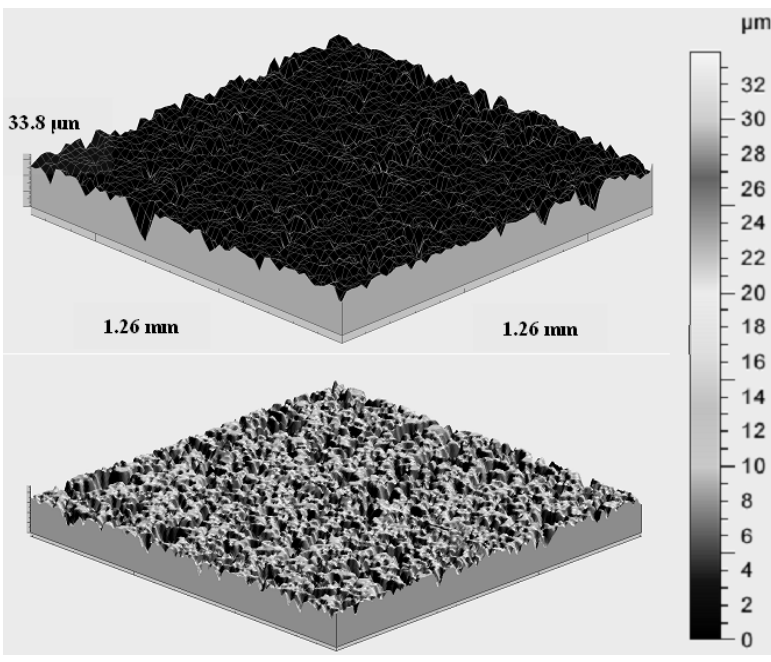

Fig.5. View of the 3D surface image and photo simulation of the powder part after sintering.

TABLE III

COMPARISON OF 3D TEXTURE PARAMETERS

\begin{tabular}{|l|c|c|c|c|c|}
\hline $\begin{array}{l}\text { Powder } \\
\text { parts after: }\end{array}$ & Sa, $\mu \mathrm{m}$ & Ssk & Str & $\begin{array}{c}\text { Vmc, } \\
\mathrm{mm}^{3} / \mathrm{mm}^{2}\end{array}$ & Sfd \\
\hline compacting & 3.06 & -1.39 & 0.706 & 0.0174 & 2.57 \\
\hline sintering & 2.65 & -1.56 & 0.766 & 0.0187 & 2.56 \\
\hline
\end{tabular}

As distinct from 2D amplitude roughness parameters the 3D texture amplitude parameter $\mathrm{Sa}$ decreases after sintering. As was mentioned earlier it could be explained by more adequate measurement results using surface texture metrology. The high values of the hybrid parameter Sfd (close to 3 maximum value of Sfd) partially confirm such hypothesis: deterministic-chaotic surface like surface of porous powder material after compacting and sintering cannot be adequately characterized by standard $2 \mathrm{D}$ roughness parameters.

An important point is that the surface after sintering is more isotropic since the value of parameter Str is closer to 1 (maximal value of $\mathrm{Str}$ ). The reason for these changes of surface condition could be argued by shrinkage of powder material during sintering. So in future we can use measurement results not only for evaluation of details quality, but for prediction of shrinkage and consequently for pressing equipment design and choosing of sintering regimes.

The highest value of functional parameter $\mathrm{Vmc}$ prove the better bearing ability of surface after sintering due to greater core material volume in contact during normal exploitation time (after wearin).
On the other hand the negatives values of amplitude parameter Ssk - surface after compacting and following sintering is characterized by negative skeweness - confirm good lubricant retention ability.

We can assume that the values of $3 \mathrm{D}$ texture parameters, especially for surface of powder part after sintering, open up wide possibilities of using new lowalloyed powder material.

\section{Friction Coefficient}

The friction coefficient as a function of time and length of friction path for compacted and sintered powder parts is shown in Fig. 6 and Fig. 7 respectively.

In both cases the stable curve of friction coefficient with relatively small fluctuation along length of friction path is observed. Average value of friction coefficient for compacted sample is $\mu=0.14$, but for sintered sample $\mu=0.22$.

After the testing of friction the visual examination of the surfaces of samples was done. As a result of visual examination it could be stated, that during testing the standard friction process occur, because no any trace of wear or plastic deformation of surface were founded out.

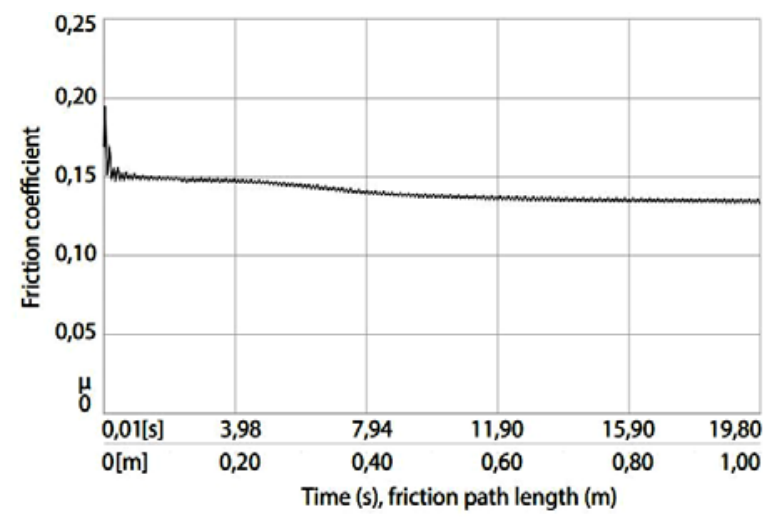

Fig.6 The friction coefficient as a function of time and length of friction path for compacted powder part.

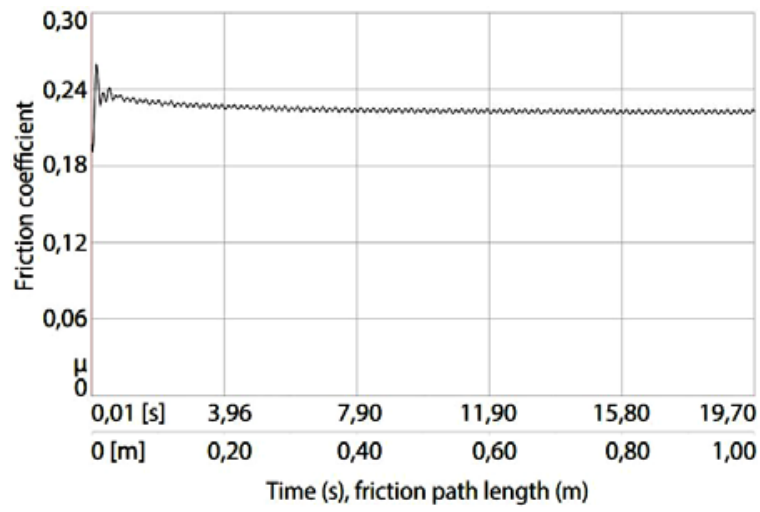

Fig.7 The friction coefficient as a function of time and length of friction path for sintered powder part. 


\section{CONCLUSIONS}

The new low-cost metal powder material based on $\mathrm{Fe}-\mathrm{C}$ compound with content of $\mathrm{Ni}$ and $\mathrm{Mo}$ up to $0.3 \%$ is offered. The powder details from this material could be produced by conventional PM technology consists of two-stage compacting and following sintering.

The complex testing of powder parts on the different stages of producing was done including evaluation of physical and mechanical properties (porosity, density and hardness), measurement and analysis of $2 \mathrm{D}$ roughness parameters, 3D texture parameters and friction coefficient as well.

It was hypothesized, that different character of changes of $2 \mathrm{D}$ and $3 \mathrm{D}$ amplitude parameters could be explained by the premise that the $3 \mathrm{D}$ metrology is more suitable for exploring deterministic-chaotic surfaces like surfaces of porous powder parts. Received values of 3D texture parameters show, that the surface of powder parts is isotropic with good lubricant retention ability and bearing ability. Appropriateness of using of new low-alloy metal powder material on the iron base for producing details of friction pair confirms the relatively small friction coefficient (after sintering 0.22) as well. One of the possible applications - bushes for braking systems of railway rolling stock. Using offered material allows reducing the product cost in complex with acceptable wear resistance and durability, which could be predicted taking into account favorable results of metrological and tribological studies.

\section{$\mathrm{V}$ ACKNOWLEDGEMENT}

This work has been supported by the Latvian Council of Science within the Project Nr. 110/2012 "Titanium compound wear-resistant nano-coatings in mechanical engineering". In this work the RTU student Pavels Stankevics was involved.

\section{REFERENCES}

[1] T. Tsutsui, "Recent Technology of Powder Metallurgy and Applications," Hitachi Chemical Technical Report, No.54, 2012.

[2] I. N. Popescu, V. Bratu, F. V. Anghelina and L. G. Toma, "The Effect of Wear Test Parameters on Tribological Characteristics of Aluminium Based Composites," The
Scientific Bulletin of Valahia University - Materials and Mechanics, Nr. 6 (year 9), pp. 83-86, 2011.

[3] S.-Z. Chen, J.-H. Chern Lin and C.-P. Ju, "Efect of Aluminum Content on Tribological Behavior of a $\mathrm{Cu}-\mathrm{Fe}-\mathrm{C}$ Based Friction Material Sliding against FC30 Cast Iron," Materials Transactions, vol. 44, No. 4, pp. 787-793, 2003.

[4] C. Teisanu and S. Gheorghe, "Development of New PM IronBased Materials for Self-Lubricating Bearings," Hindawi Publishing Corporation, Advances in Tribology, 2011.

[5] Z. Shi, P. Jian, P. Xue and D. Chen, "The Friction and Wear Characteristic of Iron-based Powder Metallurgy Materials in Scroll Compressor," Proceedings of 21st International Compressor Engineering Conference at Purdue, July 16-19, 2012, West Lafayette, Indiana, USA, West Lafayette: 2012.

[6] "Sintered Iron-Based Materials," Höganäs PM-school, [Online]. Available: http://riad.pk.edu.pl/ mnykiel/iim/KTM/ [Accessed: Nov. 11, 2014]

[7] A. Ilyushchenko and V. Savich, "Powder Metalllrgy in Belarus: Overview 2008-2013," Proceedings of 8th International Scientific Conference "Materials, Environment, Technology MET-2013”, June 19-20, 2013, Riga, Latvia, Riga: RTU. 2013.

[8] F. A. Sadykov, N. P. Barykin, I. R. Aslanyan "Wear of copper and its alloys with submicrocristalline structure," Wear, vol. 225-229, pp. 649-655, 1999

[9] J. W. Kaczmar, K. Granat, E. Grodzka and A. Kurzawa, "Tribological Properties of $\mathrm{Cu}$ Based Composite Materials Strengthened with $\mathrm{Al}_{2} \mathrm{O}_{3}$ Particles," Archives of Foundry Engineering, vol.13, special issue 2, pp. 33-36, 2013.

[10] C. Yang, "Role of Surface Roughness in Tribology: from Atomic to Macroscopic Scale," Key Technologies Band, Volume 7, 2008

[11] A. Y. Suh, A. A. Polycarpou and T. F. Conry, "Detailed Surface Roughness Characterization of Engineering Surfaces Undergoing Tribological Testing Leading to Scuffing," Wear, vol.255, pp. 556-558, Aug. 2003.

[12] L. N. Dyachkova, L. F. Kerzhentseva and L. V. Markova, Powder iron-based materials, Minsk: Belaruskaya navuka, 2004.

[13] "Exploring Surface Texture," Taylor Hobson Ltd., 4th Edition Leicester, 2003

[14] J. Petzing, J. Coupland and R. Leach, "The measurement of rough surface topography using coherence scanning interferometry," Good practice guide, No.116, National Physical Laboratory, Hampton Road, UK, 2010.

[15] E.B. Las Casas, F.S. Bastos, G.C.D. Godoy, and V.T.L. Buono, "Enamel wear and surface roughness characterization using 3D profilometry," Tribology International, vol. 41, 2008.

[16] O. Linins, J. Krizbergs and I. Boiko „Wear Estimation using 3D Surface Roughness Parameters," Key Engineering Materials, Engineering Materials and Tribology, vol. 527, pp. 167-172, 2013.

[17] A. Zawada-Tomkiewicz, "Analysis of surface roughness parameters achieved by hard turning with the use of PCBN tools," Estonian Journal of Engineering, vol. 17, pp. 88-99, 2011. 